\title{
Association between Uric Acid and Metabolic Syndrome in Homozygous Sickle Cell Patients
}

\author{
Kandji Pape Matar1, Djite Moustapha',2, Barry Nene Oumou Kesso, ${ }^{1,2}$, Sagne Rene Ngor ${ }^{1}$, \\ Thioune Ndeye Mareme1, Mbacke Ndoumbé Mame1, Ndour El Hadji Malick², Gueye-Tall Fatou², \\ Lopez-Sall Philomene ${ }^{2}$, Cisse Aynina², Diop Pape Amadou2, Gueye Papa Madieye ${ }^{1,2}$ \\ ${ }^{1}$ Laboratory of Biochemistry-Hematology, National University Hospital of Fann, Dakar, Senegal \\ ${ }^{2}$ Laboratory of Pharmaceutical Biochemistry, Faculty of Medicine, Pharmacy, Cheikh Anta Diop University, Dakar, Senegal \\ Email: kandjipapematar@gmail.com
}

How to cite this paper: Matar, K.P., Moustapha, D., Kesso, B.N.O., Ngor, S.R., Mareme, T.N., Mame, M.N., El Hadji Malick, N., Fatou, G.-T., Philomene, L.-S., Aynina, C., Amadou, D.P. and Madieye, G.P. (2021) Association between Uric Acid and Metabolic Syndrome in Homozygous Sickle Cell Patients. Advances in Biological Chemistry, 11, 142-148.

https://doi.org/10.4236/abc.2021.113010

Received: April 14, 2021

Accepted: June 14, 2021

Published: June 17, 2021

Copyright () 2021 by author(s) and Scientific Research Publishing Inc. This work is licensed under the Creative Commons Attribution International License (CC BY 4.0).

http://creativecommons.org/licenses/by/4.0/ (c) (i) Open Access

\begin{abstract}
The objective of this study was to assess the association between uric acid and the metabolic syndrome and its components in homozygous sickle cell patients. This is a prospective case/control study of sickle cell SS patients. Each patient was matched to a control of the same sex and age \pm 2 years. In our framework, we used the criteria for defining metabolic syndrome according to International Diabetes Federation (IDF) 2009. Assay of all biological parameters was performed with the ARCHITECT ci4100, Abbot (Chicago, Illinois, USA). Data were collected with Excel 2016 software and statistical analysis was done using XLSTAT 2019 software. Student's T test was used to compare means and a p-value less than 0.05 was considered significant. The study population consisted of 100 homozygous sickle cell patients with an average age of 26 years with a sex ratio of 0.58 . The prevalence of metabolic syndrome in our population according to the IDF 2009 was $2 \%$. In our study $28 \%$ of patients presented with hyperuricemia. Uricaemia was significantly elevated in patients with components of the metabolic syndrome, in particular in $33 \%$ of patients with a large waist circumference, in $25 \%$ of hypertensive patients, in $50 \%$ of patients with hypertriglyceridemia and in $60 \%$ of patients with hypertriglyceridemia and low HDL-cholesterol levels. Significant correlations were found between uricemia and certain components of the metabolic syndrome, in particular the level of triglycerides $(\mathrm{r}=0.31, \mathrm{p}=$ $0.002)$, blood sugar $(r=0.16 ; p=0.012)$, around size $(r=0.071 ; p \leq 0.05)$, HDL-Cholesterol $(\mathrm{r}=-0.01 ; \mathrm{p}=0.018)$, PAS $(\mathrm{r}=0.076 ; \mathrm{p}=0.035)$ and PAD $(\mathrm{r}=-0.18 ; \mathrm{p}=0.0015)$.
\end{abstract}

\section{Keywords}

Sickle Cell Disease, Metabolic Syndrome, Uric Acid, IDF 2009 


\section{Introduction}

Sickle cell disease is a genetic disease characterized by the presence of abnormal hemoglobin (HbS), which has the property of polymerizing in its deoxygenated form. This polymerization is the cause of a deformation of sickle red blood cells (sickle cells) which is the cause of the pathophysiology of the disease [1]. It is the most common hemoglobinopathy in the world, it is very widespread especially in black people [2]. More than 50 million individuals carry the sickle cell gene, in Senegal the prevalence of sickle cell trait is $10 \%$ [3]. Sickle cell disease is a chronic disease, it requires regular medical supervision to prevent the onset of complications, which are often unpredictable. One of the most serious forms of sickle cell disease is homozygous SS sickle cell anemia characterized by a triad of symptoms causing various biological complications that can lead to cardiovascular disease [4]. These biological disorders are often grouped together under the name of metabolic syndrome. The latter is characterized by a constellation of abnormalities such as dyslipidemia, type 2 diabetes, and hypertension and waist circumference. Hyperuricemia potentially contributes to the development of the most metabolic syndrome abnormalities, some of which are reversible with allopurinol. It has been suggested that the abnormalities that contribute to the metabolic syndrome and cardiovascular risk are related to xanthine oxidase rather than uric acid, since this enzyme generates species reactive to oxygen [5]. However, it appears highly probable that it is the intracellular excess of uric acid, due to its ability to stimulate mitochondrial oxidative stress that is the determining factor [6]. Several studies have in fact concluded that hyperuricemia was associated with a cardiovascular risk only because it was part of the metabolic syndrome and was very frequently accompanied by arterial hypertension (hypertension), dyslipemia and diabetes, held for officials of this association [6].

\section{Materials and Methods}

This is a prospective case-control study, lasting five months from June 1, 2020 to October 10, 2020. Patient recruitment took place at the National Blood Transfusion Center (CNTS) and biological tests were carried out at the Biochemistry Laboratory of the Fann National and University Hospital Center. Included in this study were patients in whom the diagnosis of sickle cell disease (SS type) was suggested on the basis of clinical and laboratory arguments. The study did not involve patients with other conditions, pregnant women and non-consenting patients. Each patient was matched to a control of the same sex and age \pm 2 years. The blood was collected on two Dry tubes and with Na fluoride centrifuged at 3500 revolutions/min for 5 minutes. For our entire study population, we studied epidemiological (age, sex), clinical (blood pressure, waist circumference) and biological (lipid balance, fasting blood sugar, uricemia) variables. Assay of all biological parameters was performed with the ARCHITECT ci4100, Abbot (Chicago, Illinois, USA). In our study, we used the criteria for defining MS according to the IDF 2009. Statistical analysis of the results was done by Excel 2016 
software which allowed us to calculate descriptive data such as the mean, standard deviation, sex ratio and $\mathrm{p}$ value. Student's $\mathrm{T}$ test was used to compare means and a p-value less than 0.05 was considered significant.

\section{Results and Discussion}

Our study population consisted of 100 sick subjects (sickle cell disease profile SS) matched with 100 control subjects. The average age of our subjects was 26 years old with extremes 13 and 51 years old. Analysis of the results of our study population showed a proportion of $63 \%$ women versus $37 \%$ men (Table 1 ).

The comparative analysis of the means of the biological parameters between patients and controls showed significant differences, except with blood sugar ( $\mathrm{p}$ $=0.37)$. The study of the association of defining criteria according to the IDF in the same individual showed a prevalence of $2 \%$ for MS (Figure 1).

Analysis of the components of MS revealed that $12 \%$ of patients had a large waist circumference, while $2 \%$ of the population had hypertension. $2 \%$ of patients presented with hypertriglyceridemia. HDL-C levels were lowered in $73 \%$ of patients. In our study population, no patient had a blood sugar $>1.10 \mathrm{~g} / \mathrm{L}$. Of our entire study population $28 \%$ had hyperuricaemia (Figure 2 ).

The distribution of the components of the MS by sex shows for the large waist circumference a predominance of women (100\%) of which $33 \%$ had hyperuricemia. The results of the sex distribution for the decrease in HDL-C revealed frequencies of $71.23 \%$ and $28.77 \%$ respectively in women and men, the frequency of hyperuricaemia in this subgroup was $40 \%$ and $60 \%$ respectively among men and women. The prevalence of hypertensive subjects was $50 \%$ in both sexes, it is the same with hypertriglyceridemia. $25 \%$ of hypertensive subjects (women) had hyperuricaemia (Table 2).

The study of the association between metabolic syndrome and uricaemia shows significant positive correlations between serum uric acid concentrations with

Table 1. General characteristics of the population.

\begin{tabular}{ccc}
\hline & Case & Control \\
\hline Number & 100 & 100 \\
Average age (years) & $26 \pm 2$ & $26 \pm 3$ \\
Sex-ratio & 0.58 & 0.58 \\
\hline
\end{tabular}

Table 2. Frequencies of the components of MS and hyperuricaemia by sex.

\begin{tabular}{ccccc}
\hline \multirow{2}{*}{ MS components } & Man & Women & \multicolumn{2}{c}{ Hyperuricemia } \\
\cline { 4 - 5 } & & & Man & Women \\
\hline Large waist circumference & $0 \%$ & $100 \%$ & $0 \%$ & $33 \%$ \\
HTA $\geq 130 / 85$ mmHg & $50 \%$ & $50 \%$ & $0 \%$ & $25 \%$ \\
High TG > 1.50 g/1 & $50 \%$ & $50 \%$ & $50 \%$ & $50 \%$ \\
HDL-c low & $28.77 \%$ & $71.23 \%$ & $40 \%$ & $60 \%$ \\
\hline
\end{tabular}




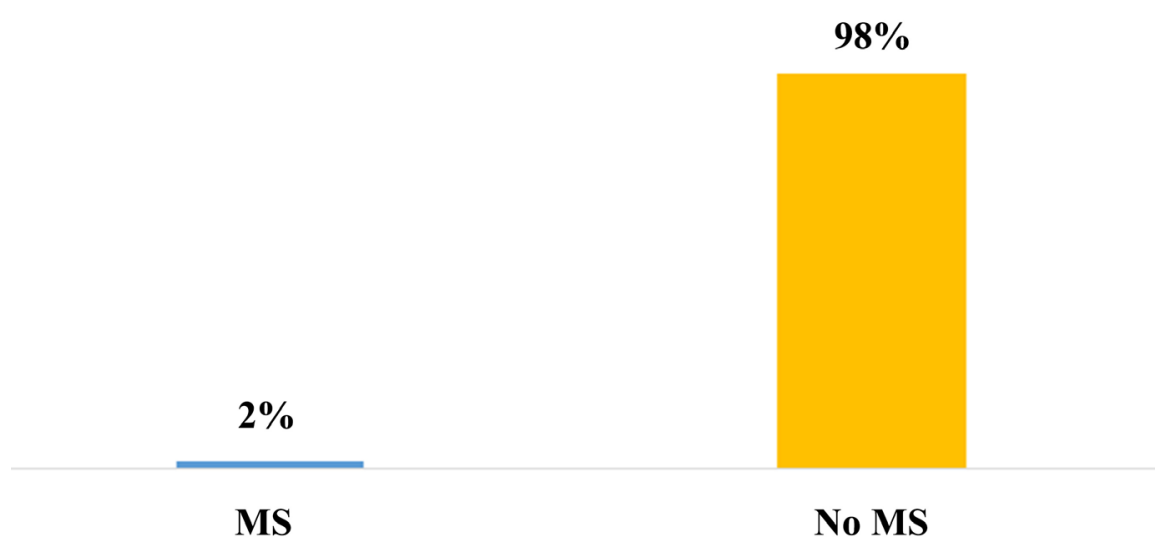

Figure 1. Frequency of MS in our population.

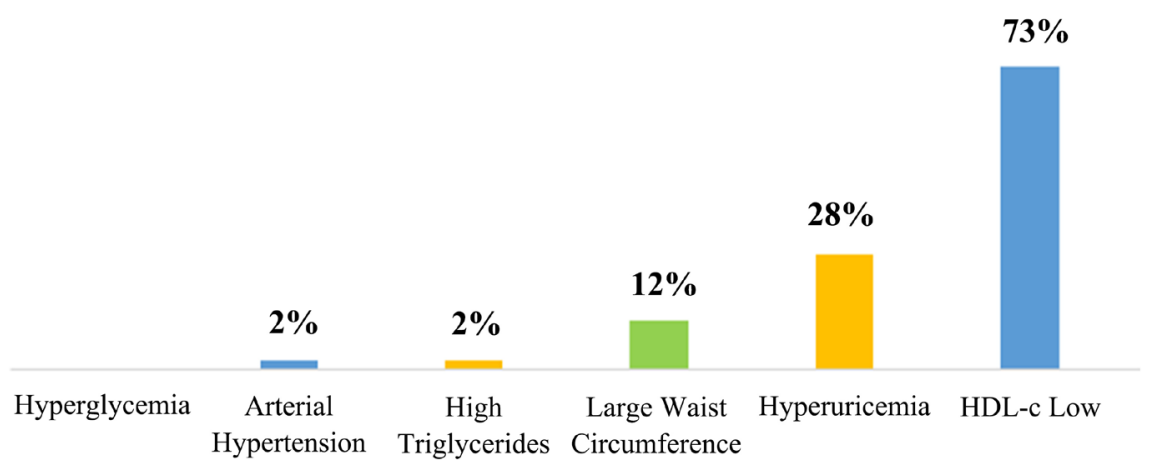

Figure 2. Frequencies of components of MS hyperuricaemia in patients.

different parameters such as serum triglyceride concentrations $(\mathrm{r}=0.31 ; \mathrm{p}=$ $0.002)$, and the waist circumference $(r=0.071 ; p \leq 0.05)$, blood sugar $(r=0.16 ; p$ $=0.0121)$ and systolic blood pressure $(r=0.076 ; p=0.0035)$, significant negative correlations between uric acid and HDL-C level $(r=-0.01 ; \mathrm{p}=0.018)$, diastolic blood pressure $(\mathrm{r}=-0.18 ; \mathrm{p}=0.0015)$ were found (Table 3 ).

Sickle cell disease is the most common genetic disease in the world. It is characterized by symptoms that can lead to serious cardiovascular complications [4]. Metabolic syndrome is a combination of factors that increase the risk of cardiovascular complications. Uric acid, due to its ability to stimulate mitochondrial oxidative stress, is an early predictor of cardiovascular events and constitutive abnormalities of metabolic syndrome [7]. It is in this context that we have set ourselves the general objective of evaluating the association between uricemia and the metabolic syndrome and its components. Exploitation of our results showed that the average age of our population was 26 years, with extremes of 13 and 51 years. This result reflects the increased life expectancy of sickle cell patients [8]. A study carried out in Dakar by Gueye Tall and al found a result of 27.3 years similar to our [6]. This increase in the life expectancy of sickle cell patients could be due to an improvement in the conditions of care and monitoring of sickle cell patients in Africa. In our study population, $2 \%$ met all of the criteria required to suggest a metabolic syndrome. Foluso and al in the USA reported a 
Table 3. Correlations between uricemia and the different components of the metabolic syndrome.

\begin{tabular}{ccc}
\hline & \multicolumn{2}{c}{ Uricemia } \\
\cline { 2 - 3 } variables & $\mathbf{r}$ & $\mathbf{p}$ \\
\hline Fasting blood sugar $(\mathrm{g} / \mathrm{l})$ & 0.16 & 0.012 \\
Waist circumference & 0.071 & $<0.05$ \\
HDL-C (g/l) & -0.01 & 0.018 \\
TG (g/l) & 0.31 & 0.002 \\
SBP (mmHg) & 0.076 & 0.035 \\
DBP (mmHg) & -0.18 & 0.0015 \\
\hline
\end{tabular}

rate of $8.6 \%$ [9]. This difference can be explained by the criteria chosen for the definition of MS according to the organizations, environmental factors but also by ethnic origin. The analysis of the prevalence of the different criteria of the metabolic syndrome according to the definition of the IDF made it possible to show that $73 \%$ of the patients had a low HDL-C level, $12 \%$ of the cases had a high waist circumference and $2 \%$ had high triglyceride levels and hypertension. Our results are similar to those of Foluso and al [6]. We also noticed a female predominance for the high waist circumference and low HDL-c. This result can be explained by our sex ratio but also by the increased sedentary lifestyle among women. In our study we found hyperuricemia in $28 \%$ of cases, this result is similar to that of Ateba and al who found a prevalence of $34 \%$ in their population [9]. This increase in uric acid is often encountered during hemolysis, nucleic acid synthesis, erythropoiesis and especially the decrease in its urinary excretion following impaired renal function in sickle cell patients. Uricaemia is significantly elevated in patients with components of the metabolic syndrome, in particular in $33 \%$ of patients with a large waist circumference, in $25 \%$ of hypertensive patients, in $50 \%$ of patients with hypertriglyceridemia and in $60 \%$ of patients with Low HDL-cholesterol levels. Our results are similar to those of Zayani et al. [10]. Hypertriglyceridemia may be the consequence of a synthesis from the increase in substrates secondary to excess intra-mitochondrial uric acid, the decrease in HDL-cholesterol levels, another trait of the metabolic syndrome, is usual in subjects with chronic hyperuricaemia [11]. Hyperuricemia induces endothelial dysfunction through an antiproliferative effect, and induces an increase in blood pressure linked to a modification of the intrarenal vascularization [12]. Pilot studies in humans suggest that lowering uricemia leads to improvement in hypertension [13].

\section{Conclusion}

Sickle cell disease is now a real public health problem, it is the most common hemoglobinopathy in the world. Complications related to its homozygous form can lead to an increased cardiovascular risk. The presence of MS in a sickle cell 
patient increases the risk of CVD, asymptomatic hyperuricaemia is associated with most of the functional and metabolic disturbances involved in the pathophysiology and definition of the metabolic syndrome. Our study shows an association between uraemia and the metabolic syndrome and its various components. It is therefore important for practitioners to recognize the MS in consultation in order to identify these patients who should benefit from regular medical follow-up.

\section{Conflicts of Interest}

The authors declare no conflicts of interest regarding the publication of this paper.

\section{References}

[1] Strouse, J. (2016) Sickle Cell Disease. Handbook of Clinical Neurology, 138, 311-324. https://doi.org/10.1016/B978-0-12-802973-2.00018-5

[2] Wajcman, B.J. (2004) Epidémiologie de la drépanocytose. The Practitioner's Review, 54, 1531-1533.

[3] Diop, S. and Diop, D. (2010) Facteurs prédictifs des complications chroniques de la drépanocytose homozygote chez l'adulte à Dakar. Tropical Medicine, 70, 471-474.

[4] GUEYE, T.F., NDOUR, E.H.M., CISSE, F., GUEYE, P.M., et al. (2004) Perturbations de paramètres lipidiques au cours de la drépanocytose. Journal of Scientific Research/ Health Sciences, 2, 35-41.

[5] George, J., Carr, E. and Davies, J. (2006) Highdose Allopurinol Improves Endothelial Function by Profoundly Reducing Vascular Oxidative Stress and Not by Lowering Uric Acid. Circulation, 114, 2508-2516. https://doi.org/10.1161/CIRCULATIONAHA.106.651117

[6] Foluso, J., Diako, S.M., Nelson, J., Cichowitz, C., et al. (2019) Metabolic Syndrome among Adults Living with Sickle Cell Disease. Bloods Cells, Molecules and Diseases, 74, 25-29. https://doi.org/10.1016/j.bcmd.2018.10.005

[7] Gagliardi, A.C., Miname, M.H. and Santos, R.D. (2009) Uric Acid: A Marker of Increased Cardiovascular Risk. Atherosclerosis, 202, 11-17.

https://doi.org/10.1016/j.atherosclerosis.2008.05.022

[8] Gueye, P.M., Gueye, T.F., Seck, M., Kane, M.O., et al. (2014) Aggravation de l'anémie et polymorphisme de l'haptoglobine au cours de la drépanocytose au Sénégal. International Journal of Biological and Chemical Sciences, 8, 975-982. https://doi.org/10.4314/ijbcs.v8i3.13

[9] Ategba, G.N., Sack, N.F.F., Ategba, M.H.G., Ngogang, J., et al. (2017) Exploration de la fonction glomérulaire chez les drépanocytaires homozygotes à Yaoundé. Health Sciences and Disease, 18, 65-69. https://www.hsd-fmsb.org

[10] Zayani, Y., Elasmi, M., Feki, M., Hadj, T.S., et al. (2010) Uricémie et syndrome métabolique dans la population du grand Tunis. Elsevier Masson, 269, 677-685. https://doi.org/10.1016/S1262-3636(10)70416-X

[11] Peng, T.C., Wang, C.C. and Kao, T.W. (2015) Relationship between Hyperuricemia and Lipid Profiles in US Adult. BioMed Research International, 2015, 127596. https://doi.org/10.1155/2015/127596

[12] Soletsky, B. and Feig, D.I. (2012) Uric Acid Reduction Rectifies Prehypertension in 
Obese Adolescents. Hypertension, 60, 1148-1156.

https://doi.org/10.1161/HYPERTENSIONAHA.112.196980

[13] Feig, D.I., Soletsky, B. and Johnson, R.J. (2008) Effect of Allopurinol on Blood Pressure of Adolescents with Newly Diagnosed Essential Hypertension: A Randomized Trial. JAMA, 300, 924-932. https://doi.org/10.1001/jama.300.8.924 